\title{
A New Probe into the Strategic Steps of Japan's Annexation of Korea in Modern Times: Focusing on the Treaty Relations Between Japan and the World's Powers
}

\author{
Fan Xinyue
}

School of Asian and African Studies, Shanghai International Studies University, Songjiang, Shanghai, China 2909203913@qq.com

\begin{abstract}
The merger of Korea and Japan in 1910 undoubtedly opened the "cold winter era" in North Korea's history. Even though a hundred years have passed, the 'hatred' of the Korean nation's subjugation has still not disappeared. In the past, how Japan "legally" occupied North Korea under the modern Western treaty system without any condemnation from the international community is still worth considering. This article takes the treaties signed between Japan and the world's powers as an entry point, and discusses the strategic steps taken by Japan to annex North Korea in modern times.
\end{abstract}

Keywords: Japan, North Korea, treaty, international law

\section{近代日本吞并朝鲜的战略步骤新探: 以日本与世界列强 诸国签订的条约关系为中心}

范新月

上海外国语大学东方语学院, 松江, 上海, 中国 2909203913@qq.com

\section{摘要}

1910 年的韩日合并, 无疑开启了朝鲜历史上的 “寒冬时代”, 而今百年虽过, 韩民族的亡国之 “恨” 依然未消。 回数过往, 日本是如何在近代西方条约体制下 “合法” 占领朝鲜且未受到国际社会的任何谴责依旧值得考量。 本文将日本与世界列强诸国签订的条约作为切入点, 对近代日本吞并朝鲜的战略步骤进行了探讨。

关键词:日本, 朝鲜, 条约, 国际法

\section{1. 引言}

朝鲜与日本隔海相望, 地缘位置使其自古便饱受 日本之侵犯。据《三国史记》记载: “新罗始祖八年, 倭人行兵, 欲犯边, 闻始祖有神德, 乃还。” 7 世纪 中叶, 日本也曾出兵朝鲜半岛, 助援百济抵抗新罗; 1592 年, 丰臣秀吉又发动全面侵朝战争, 但以失败 而终。1868 年日本明治维新之后, 效仿西方走上了 对外扩张的道路, 再度把侵略矛头指向了朝鲜。结果, 日本在短短三十四年间 (从 1876 年迫使朝鲜开港到
1910 年完全吞并朝鲜), 实现了蓄谋已久的侵略野心 [1]。

在近代历史上, 列强诸国如果要兼并一个主权国 家, 仅仅靠事实上的占领仍无法达到目的, 还需要获 得国际法的承认。也就是说, 基于近代西方条约体制, 需要相关大国的认同和相关条约的签订 [8]。那么, 在西方列强普遍向外扩张的近代, 羽翼未丰的日本是 如何排除大国干预, 将曾是满清藩属国的朝鲜纳为自 己的殖民地, 又是如何公开侵占朝鲜而未受到国际社 会的任何谴责? 
本文试图以日本与周边大国签订的一系列条约 为主要线索, 进一步探讨这些条约的缔结背景、内容 的基础上, 着重对其影响进行剖析, 从而揭露日本帝 国主义是如何步步为营, 为最终吞并朝鲜铺平道路的。

\section{2. 瓦解中朝宗藩关系}

李氏朝鲜自建立之日起, 便主动加入了东亚华夷 秩序，恪守中朝传统的宗藩关系。在这种关系中，朝 鲜国王要接受中国皇帝的册封, 并负有向中国皇帝进 贡的义务; 而中国在朝鲜发生内乱和受到外敌侵犯之 时, 也有派兵帮其平息或退敌御边的义务。这种传统 的宗藩关系, 对极欲实现对外扩张的日本而言, 显然 是首先要冲破的一大障碍。因此, 自 19 世纪 70 年代 起, 日本按照国际法原则, 相继与中国签订《中日修 好条规》, 《天津条约》, 《马关条约》, 意在彻底否定 中国对朝鲜的宗主国地位, 以扫清吞并朝鲜之障碍。

\section{1《中日修好条规》: 日本打开与朝鲜 交涉的方便之门}

1868 年 3 月, 日本明治天皇发表《御笔信》, 申 明要 “经营四方, 安抚亿兆, 冀终开拓万里之波涛, 布国威于四方”，公然提出奉行海外扩张政策。是年 10 月，明治政府命令九州岛对马藩把 “王政复古”、 “维新改元”一事告知朝鲜政府, 谋求对朝建交, 但 因书契格式上透露出对朝鲜的轻慢, 终被朝鲜方驳回。 日本外务省再度商讨对朝策略后, 决定采取 “远交近 攻” 的方案, 即先派使臣与中国缔结条约, 建立与中 国的平等关系, 再以此逼迫属国朝鲜屈服于日本。为 达到这一目的, 日本积极向中国发起外交攻势 [5]。 1870 年 7 月, 日本外务大丞柳原前光到访中国, 并以 中日同为受侵略国家, 应共同防御西方列强为由, 诱 使李鸿章建交立约。最终, 1871 年 9 月, 日本与清 政府缔结《中日修好条规》 [2]。

《中日修好条规》共计十八款, 主要内容有: 两 国所属邦土, 各以礼相待, 不可稍有侵越; 两国均可 派使臣, 驻扎京师; 两国沿海各口岸, 彼此均应指定 处所, 准听商民来往贸易; 两国指定各口, 可互设理 事官, 处理经济和法律纠纷事宜等 [6]。由于条约规 定的权利和义务都具有相互性, 《中日修好条规》被 认为是中日之间的平等条约。

尽管如此, 该条约给中日双方所带来的实际利益 却是不对等的。简言之, 该条约并没有给中方带来多 少实际利益, 但对日本而言却是打开了与朝鲜交涉的 方便之门。日本当初极力诱使李鸿章建交立约之目的 就在于谋取与中国的同等地位, 以便在往后的日朝交 涉中, 使对中国恪守事大藩属之礼的朝鲜置于下风, 进而陷其于被动地位。《中日修好条规》的签订, 达 成了日本利用中国压制朝鲜的最初企图。不仅如此, 日本依此条规从法理上成为了朝鲜之 “上国”, 这又 为入侵朝鲜增添了被认可的 “合理性。”
张启雄教授曾坦言道, “自《中日修好条规》缔 结后, 日本 $\mathrm{J}=\mathrm{C}, \mathrm{C}>\mathrm{K}, \mathrm{J}>\mathrm{K} \mathrm{C}=$ 中国, $\mathrm{J}=$ 日本, $K=$ 朝鲜）的观念日盛; 又以满清出身北狄, 遂视清为夷, 以已为华, 取清而代之的观念, 日益强 盛。于是起兵 “进出” 中华世界。” 《中日修好条规》 使日本的扩张意识日益膨胀, 而朝鲜作为日本拆分传 统华夷体系的最佳进路, 不可避免地成为了日本对外 扩张的首要目标。

\section{2 《天津条约》: 日本获得与中国在朝鲜 的同等地位}

《中日修好条规》签订之后，日本便积极同朝鲜 展开了开国通商的交涉。1876 年, 日本以武力手段 迫使朝鲜开港, 并与朝鲜签订了《江华条约》。该条 约的第一款就明示 “朝鲜系自主之邦, 保有与日本国 平等之权”, 从而在法律层面上否定了中朝宗藩关系, 成为日本在征韩道路上实质性的开端。

1882 年 7 月, 朝鲜国内爆发壬午兵变, 事后日 本以赔偿各种损失为由, 再次胁迫朝鲜签订《济物浦 条约》, 获得了在朝驻兵权。但在该场兵变中, 由于 清朝出兵镇压, 致使日本趁机企图干涉朝鲜内政的计 划落空。因此, 不甘失败的日本便积极谋划摧垮中国 之于朝鲜的宗主权, 开始实施对朝鲜的笼络政策。 1884 年 12 月, 日本挑唆朝鲜开化党发动了 “甲申政 变”, 但不到三天, 又被驻朝清军所镇压。事后, 日 本反而借口 “使馆被焚”, “侨民被害”, 要求朝中两 国谢罪、赔款、惩凶，逼迫清政府签订了《天津条约》 (1885 年 4 月)。

《天津条约》是中国外交史上的一次大失败。首 先, 中国向日本妥协签订此条约无异于承认日本干涉 朝鲜内政, 颠覆朝鲜政府的行为毫无过错, 这不仅使 日本逃避了罪责, 更纵容了日本在朝肆意妄为之行径。

其次，就《天津条约》内容而言，除规定中日同 时从朝鲜撤军之外, 其最大弊端在于它的第三款: “将 来朝鲜国若有变乱重大事件, 中、日两国或一国要派 兵, 应先互行文执照, 及其事定, 仍即撤回, 不再留 防。”[6]由此, 日本第一次在朝鲜取得了与中国对等 的权利和义务, 从而在客观上形成了中日两国共同保 护朝鲜的局面, 结果中国对朝所持有的 “宗主权” 之优势已荡然无存。诚如梁启超所言: “江华湾条约 使朝鲜自认非我属国, 天津条约使我认朝鲜非我属 国。” 当然, 这一条款还具有更大隐患, 那便是它默 认了日本与中国均有出兵朝鲜半岛的权利, 这为后来 日本挑起甲午战争提供了借口。

\section{3 《马关条约》：日本彻底摧垮中朝宗 藩关系}

1894 年 2 月, 朝鲜南部发生 “东学党” 领导的 农民起义。起义军声势浩大, 发展迅速。朝鲜政府感 到局势难以控制, 遂决定向清朝借兵助剿。正当请朝 


\section{1《西一罗森议定书》: 日本确立在朝经 济主导权}

对于俄国而言, 朝鲜具有保障其在远东地区既得 利益和为其提供不冻港的潜在价值。因此, 当日本在 甲午战争中击败中国, 并通过签订《马关条约》事实 上废除中朝宗藩关系之后, 俄国已无法容忍日本独占 朝鲜的野心膨胀, 遂支持闵妃政权驱逐朝鲜国内的亲 日势力。面对来自俄国的挑战, 日本策划了 “乙未政 变” (1895 年 10 月), 以搼除朝鲜政府中的亲俄派。 不料, 翌年 2 月亲俄派再次得势, 造成了高宗迁入俄 国公使馆并受俄国控制的异常局面。此后, 日本在朝 鲜一度处于劣势, 直至 1898 年 3 月, 俄国欲向中国 强租旅顺、大连, 考虑到来自日本的阻力, 不得不在 朝鲜问题上做出让步。同年 4 月 25 日, 日俄在东京 签订的《西一罗森议定书》, 正是俄国向日本妥协的 产物。

该条约共计三款，其第一款和第二款确认了 “朝 鲜之主权及其完全独立，不干涉其内政”，并规定今 后向朝鲜举荐军事教官和财政顾问时, 未经日俄两国 事先相互协商, 不得采取任何措施。这样, 在对朝鲜 政府的政治影响方面, 日本恢复了与俄国的对等地位。 事实上，在条约协商的过程中，俄国已经应日本要求 撤回了在朝鲜的俄籍教官和财政顾问亚历克赛耶夫, 并关闭了才经营一个半月的俄朝银行（1898 年 4 月 12 日)。日本通过该条约再次确保了俄国停止向朝鲜 进行政治渗透。

该条约的第三款要求俄帝国政府绝不妨碍日朝 两国间工商关系之发展。这实际上意味着俄国承认了 日本在朝鲜经济领域的支配地位，随后日本在朝鲜的 经济优势更加突显, 终于获取了在朝鲜铺设京釜铁路 的权利（1898 年 9 月); 而俄国在该条款的制约下, 不得不拒绝与朝鲜政府发生任何金融关系, 对当地俄 国企业也不予任何援助 [9]。

可以看出, 《西一罗森协定》是日俄以 “满韩交 换” 为基点所签署的, 日本凭借该条约扭转了先前的 被动与劣势, 重新确立起了在朝鲜的主导地位。

\section{$3.2 《$ 朴茨茅斯条约》：日本对朝统治权 获俄国承认}

通过签署《西一罗森协定》, 日本虽然恢复了在 朝鲜的优势地位, 但并不足以把俄国势力彻底从朝鲜 驱逐出去。当俄国租借旅顺、大连成功之后, 又在马 山浦与日本展开争夺。1900 年 7 月, 俄国利用参加 八国联军镇压义和团之机, 派兵占领了中国东北三省, 此举不仅直接损害了日本在满洲的权益, 还威胁到了 日本在朝鲜的发展, 从而增加了俄国对日本的姤恨。 1903 年 8 月, 日本正式向俄国提出交涉, 要求俄国 承认日本在朝鲜享有 “卓越利益”, 但俄国的底线是 要保证朝鲜（至少朝鲜北部）的 “中立”, 双方分歧 明显, 导致外交谈判陷入僵局。1904 年 2 月 6 日, 
日本照会俄国终止谈判,并断绝外交关系。2 月 8 日, 日本海军不宣而战, 突袭了俄国驻扎在中国旅顺口的 舰队，日俄战争爆发。在交战过程中，俄方由于补给 困难和指挥无能而屡遭失败, 最终于 1905 年 9 月被 迫签订《朴茨茅斯条约》。

《朴茨茅斯条约》的《正约》第二条即为有关朝 鲜问题的规定，即俄罗斯政府承认日本国于朝鲜之政 治军事经济上均有卓绝之利益, 如指导保护监理等事, 日本政府视为必要者即可措置, 不得阻碍干涉 [6]。 此外, 俄国同意不在俄朝边境采取任何侵犯朝鲜领土 安全的军事措施。

日本通过这一条款, 使俄国正式承认了日本对朝 鲜的统治权。《朴茨茅斯条约》签订后, 日俄在朝鲜 半岛上的均势局面被日本独霸所替代, 日本顺势加快 了将朝鲜殖民化的进程。1905 年 11 月, 日本便迫使 朝鲜政治实体与之签署《乙巳保护条约》, 瞳取了朝 鲜的外交主权并在朝鲜实施 “统监政治”, 使朝鲜沦 为了名符其实的日本的 “被保护国”。

不仅如此, 《朴茨茅斯条约》的签订, 作为后起 的亚洲国家战胜欧洲列强之先例, 标志着近代传统东 北亚国际政治格局的变化, 确立了日本在国际舞台上 的强国地位, 这无疑为最终吞并朝鲜创造了更为有利 的条件。正如美国总统西奥多 - 罗斯福所言: “日本 博得了令人惊异的胜利, 取得了显著的报酬。日本获 得了对满洲及朝鲜制驭权…在太平洋内除了英国之 外, 造成了任何国家也难以匹敌的优势。”

\section{4. 获取列强诸国的默认与支持}

日本通过日俄战争欲摘得的战果即为独霸朝鲜 半岛。为了避免战后再次发生类似三国干涉 “还辽” 等意外情况的发生, 日本决定事先征得西方列强的支 持和谅解。1905 年 5 月, 随着俄国败局渐趋明朗, 日本开始将重心转移至与欧美大国的外交谈判上。 1905 年 7 月, 通过相互保证和利益交换, 日本首先 与美国达成了《塔夫脱一桂太郎密约》, 8 月又与英 国签订了《第二次英日同盟条约》。1907 年 6 月, 日 本继而与法国达成了《日法协定》。至此, 日本相继 得到了西方列强对其兼并朝鲜的认可, 为最后吞并朝 鲜铺平了道路 [12]。

\section{1《塔夫脱一佳太郎密约》：日本对朝 统治权获美国承认}

1868 年日本实行明治维新之后，随着日本在东 亚的崛起, 美国的东亚政策发生了历史性转折。即: 抛弃欧洲伙伴, 单独奉行亲日政策。美国一度认为日 本握有 “开启东方的钥匙”, 并试图通过美日合作削 弱英国等欧洲国家在东亚的影响, 从而造成一种有利 于美国的 “均势”。美国对朝鲜的主要诉求在于发展 贸易, 但考虑到朝鲜有限的资源和贸易市场, 美国一 直将朝鲜置于外交政策中的边缘位置, 甚至在必要时
能够牺牲朝鲜，通过确认日本对朝鲜的殖民统治来 “取悦”日本，以实现美国整体国家利益的最大化。

美国对日的友好态度, 日本自然也心领神会。为 了进一步巩固日美关系, 日本于 1904 年 2 月派遣曾 为内阁司法大臣的金子坚太郎担任大使赴美。在与美 国建立大使级外交关系前, 派遣高于公使级别的日本 天皇特派大使赴美展开外交，日本可谓是“用心良苦”。 但不可否认，日本的积极示好换取了美国对其在朝扩 张的支持。在日俄战争期间, 美国政府对于日本占领 朝鲜、强迫签署一系列协定等一切行为并未表示异议。 如, 1905 年 1 月 25 日, 当日本攻陷旅顺后, 小村寿 太郎外相通过日本驻美公使高平小五郎向美国传达 日本“关于恢复和平后的满、朝、旅顺的意图及希望” 之时, 罗斯福当即回复称: “日本必须确保旅顺, 必 须确保朝鲜, 这两点已成定局。”随后桂太郎首相和 抵达日本的美国陆军长官塔夫脱交换了有关 “朝鲜问 题” 的备忘录, 即《塔夫脱一桂太郎密约》(1905 年 7 月 27 日)。

《塔夫脱一桂太郎密约》核心内容有二: 一是桂 太郎所表示的日本对菲律宾不抱任何侵略性的意图; 二是塔夫脱所表示的美国认可日本军队建立对朝鲜 的统治权权, 此乃日俄战争合乎逻辑的结果, 这将为 东方的持久和平做出直接的贡献。在这份密约中, 菲 律宾和朝鲜成为了日美双方利益交换的筹码。日本政 府以保障美国统治菲律宾为代价, 再一次换取了对朝 鲜实现垄断性统治方面的美方承诺。

日本《国民报》对这一备忘录做了如下评述: “实 质上这是日美同盟。由于特殊的国内条件，美国不能 公开结盟, 但我们应该经常记住他是我们的盟国, 虽 然还没有正式的条约跟我们连接起来。” 诚如其言, 美国对日本的支持已经不亚于一个同盟所为: 1905 年 11 月, 美国积极响应日本请求, 带头召回了驻朝 公使摩根、关闭了美国驻朝公使馆, 并将朝鲜从美国 国务院建交国家名单中删除, 列入日本条目之下。这 是美国默认朝鲜为日本殖民地而非主权国家的表现， 而在美国的 “示范” 下, 各国相继召回了驻朝公使并 关闭了在朝鲜的公使馆。正是由于美国的协助, 日本 得以扫清了影响其全面控制朝鲜的象征性障碍。

\section{2 《第二次英日同盟条约》：日本对朝 统治权获英国承认}

从 19 世纪中期开始, 英国的全球霸权政策便是 维持世界霸主地位, 保障英国在世界市场中所享受的 特权和利益, 以及消除针对英国霸权的任何可能的威 胁。朝鲜对于英国而言, 其重要价值不在于潜藏的经 济利益, 而在于特殊的地理位置。鉴于这一时期俄国 在远东地区对殖民地的争夺, 英国对朝政策的主要目 标便是防止沙俄借道朝鲜半岛南下。然而, 远东的国 际局势和远距离作战成本, 使英国深刻认识另寻该地 区盟友作为战略支撑之必要。这与因 “三国干涉还辽” 事件与俄国反目为仇的日本不谋而合。其后, 英日双 
方为共同阻止俄国南下越走越近，终于签订了《英日 同盟条约》(1902 年 1 月), 双方正式确立了同盟关 系。

到日俄战争后期, 日本为实现其独霸朝鲜之野心, 迫切感到续订《英日同盟条约》之必要性, 以便日后 与俄国谈判时占据有利地位。因此, 1905 年 2 月, 日本外相小村寿太郎在纪念《英日同盟条约》签订的 三周年大会上发表演说, 公开表示 “希望英日之间的 同盟关系能继续得到巩固和加强” [13], 此举也得到 了英国方面的积极回应。8 月 12 日, 经过多轮外交 谈判, 英日双方在伦敦签订了《第二次英日同盟条约》 [7]。

根据该条约, 一方面英国承认日本在朝鲜拥有政 治上军事上及经济上之卓越利益, 认同日本在朝鲜为 保护及增进此类利益, 有必要采取其认为必要之措置, 以行指导、监督及保护之权利 (第三款), 另一方面 日本也承认英国在印度的特殊权益, 以及英国为保护 英属地而采取的必要措施的权利 (第四款)。显然, 日本以承认并支持英国在印度的殖民权益为条件, 换 取了英国对日本统治朝鲜的认可与支持, 从而进一步 巩固了自身在朝鲜的排他性地位 [12]。

《第二次英日同盟条约》的签订对日本在朝鲜半 岛的侵略扩张起到了推波助澜的作用。在迫使朝鲜签 订《乙巳保护条约》之前, 日本政府曾通过驻英大使 秘密通告英国外务大臣兰斯多恩（1905 年 9 月）。兰 斯多恩再次明确表示: “(大不列颠）政府根据新同盟 协约规定，不仅不反对日本政府对朝鲜采取的措施， 反而非常赞同。” 获知英国政府的上述表态, 日本更 加肆无忌惮地推进了将朝鲜 “保护国化” 的方针。因 此, 英国对日本扩张行为的支持无疑是日本 “韩日合 并”之阴谋得以成功的重要因素, 有学者甚至指出,

“如果没有得到英国的默许和支持, 日本肯定不敢吞 并朝鲜, 即使敢吞并朝鲜也未必能于 1910 年就吞并 它。”[4]

\section{3 《日法协定》：日本对朝统治权获法 国承认}

先布教，后殖民化，系法国资本主义对外侵略之 显著特点。换言之, 先通过传播宗教把殖民化罪恶行 径加以合法化之后, 再以通商贸易手段把落后国家的 经济拖进到殖民化轨道, 最终强制实现政治殖民化。

自 19 世纪初开始, 法国就遣派多名神父前往朝 鲜进行传教活动, 以扩大自身势力并诱使朝鲜门户开 放。然而 1866 年 “丙寅洋扰” 事件之后, 法国对朝 鲜的渗透有所收敛。例如, 1882 年朝鲜全面开放门 户之后, 法国是欧美列强中最后与朝鲜缔结通商条约 的国家, 而其扩张重心一度转到了资源丰富的印度支 那地区。与此同时, 法国对日本的崛起一直抱有警觉 的态度, 它认定日本为远东地区不可小觑的威胁。加 之 1893 年法国又与俄国结成了军事同盟, 因而面对 日俄在朝鲜和满洲的激烈冲突, 法国采取了 “挺俄拒
日”之策 $[3]$ 。

但是, 1905 年 5 月, 当日本在对马海战大胜俄 国之时, 法国开始意识到, 继续与日本为敌, 则有远 东殖民地不保之风险。因此, 1907 年 3 月, 法国外 交部长向驻巴黎的日本大使粟野慎一郎提议, 希望缔 结日法协定, 以划分势力范围, 确保双方利益不受损 害。

面对法国示好之举，日本更是远谋深算。日本深 知, 法国政府最关心的是法属印度支那的安全与和平, 为此需要签订一个条约来约束日本扩张。即便如此, 日本最终还是同意与法国和解, 原因就在于其侵略重 心局限于朝鲜半岛和中国东北地区, 与法国没有绝对 的利益冲突。因此, 日本希望通过与法国缔结条约的 方式, 换取他们对朝鲜的统治权的认可, 以解除后顾 之忧。1907 年 6 月 10 日, 在日法双方互有所图的前 提下，正式签订了《日法协定》。

《日法协定》虽非日本主动而为, 却在条约签订 过程中反客为主, 占据着优势地位。通过签署该协定, 不仅使法国承认了日本对台湾统治的合法性, 还承认 朝鲜、中国满洲、福建省均为日本势力范围; 而作为 交换，日本也承认法国在印度支那领土的特权。

德国驻华公使雷斯克（Von Rex）曾一语道破《日 法协定》之影响: “由于这个条约, 法国没有犹豫地 承认日本在东亚的权利……对日本来说, 条约有不可 估计的价值。自从和英国结盟帮助日本成为强国后, 法国现在宣布它准备再加强这个年轻的大国……条 约是日本统治东亚更进一步的基础。” [11]总之, 世 界列强的支持壮大了日本的力量, 却加速了朝鲜的灭 亡。在该条约签订不过三年, 朝鲜完全被日本合并, 而日本多了一个总督区。

\section{5. 结 语}

自从产生具有近代意义的国际法之后, 条约就成 了国际法的体现方式。然而，这种理应反映国家之间 平等互利关系的条约制度, 在近代却为列强诸国 “弱 肉强食” 的罪恶行径提供了 “合法” 依据。

尼赫鲁曾指出，因亚洲新大国的崛起而 “初尝苦 果的是朝鲜” [10]。从瓦解中朝宗藩关系至获取列强 诸国的承认, 日本曾为吞并朝鲜处心积虑、胆大妄为, 而在其背后为虎作伥、推波助澜者正是曾貌似公允的 国际条约联盟国家。如果日本没有以条约为依据先后 排除了中、俄两大国干预，并进一步拉拢美、英、法 等大国关系狼狈为奸, 那么就很难敢冒天下之大不题 而公然吞并一个主权国家, 且事后没有受到国际社会 的任何谴责。因此, 日本称霸亚洲的狂妄野心及国际 条约联盟国之间肮脏的交易, 直接酿成了大国地缘政 治博弯中的 “弱国政治的悲剧”。

\section{REFERENCES}

[1] Cao ZP.(1993)Modern History of Korea (1863-1919). 
Oriental Press, Shanghai.

[2]Cao ZP. (2015)The Japanese imperialists' policy of occupying North Korea $(1904 \sim 1910)$ (3). Contemporary Korea, 1-26.

[3] Chen J. (2011) Vichy French Far East Policy Research. East China Normal University Press Sh anghai.

[4] Jin GZ, (1997)Jin Guichun. The fourth volume of the general history of North Korea. Yanbian University Press, Yanji.

[5] Wang MX. (1998)Korean Modern Diplomacy and China (1861-1910). China Social Sciences Press, Beijing.

[6] Wang YS. (1979)China and Japan in the past sixty years. Life-Reading Xinzhi Sanlian Bookstore, Beijing.

[7] Yin CC. (2012) The modern beginning of the geopolitical competition on the Korean Peninsula. Shanghai International Studies University Press, S hanghai.

[8] Zhang J. (2010)The contest between China, Japan and Russia on the Korean Peninsula: 1860-1910. Northeast Normal University Press, Changchun.

[9] Zhu HY. (2014)The dual track of modern Japanese diplomacy: alliance and aggression. Social Science Archives Press, Beijing.

[10] [Japan] Nobuo Kiyosaburo. (1980) History of Japanese Diplomacy. The Commercial Press, Beijing.

[11] [Korean] Zhao JD. (2019)Modern North Korea and Japan. New Star Press, Beijing.

[12] [Korean] Kim WS. (2010)The Global History of the Anglo-Japanese Alliance and Korea-Japan Annexation, 1905-1911. Social Studies Education, 49: 121-133.

[13][Korean]Won C $\quad$ ( 2006 ) Neighboring Powers Consultation on Korean Penin sula Issues and Eulsa Treaty. History Journal, 192: 367-393. 